\title{
Measuring the impact of residential mobility on response: the case of the Millennium Cohort Study
}

\author{
Tarek Mostafa Department of Quantitative Social Science, Centre for Longitudinal Studies, Institute of \\ Education \\ t.mostafa@ioe.ac.uk
}

(Received September $2015 \quad$ Revised January 2016) $\quad$ http://dx.doi.org/10.14301/llcs.v7i3.378

\begin{abstract}
This paper examines the relationship between residential mobility and unit non-response in the first five waves of the UK Millennium Cohort Study (MCS). The objective is to ascertain whether home moves affect the likelihood of response and whether any impact persists over time. The existing literature is extended by examining the impact of moving home on the likelihood of returning to the survey after dropping out in a previous wave. The findings show that by the fifth wave of MCS more than two thirds of respondents had experienced at least one home move, with most moves happening before wave 2. Residential mobility is found to have a negative impact on subsequent response, even though this impact does not persist over time. Put differently, moving home is circumstantial and movers are likely to come back to the survey after being absent in a previous wave. The findings also shed light on the importance of tracing home movers in order to maintain the sample representativeness in a long-term longitudinal survey.
\end{abstract}

\section{Keywords}

Home moves, response, longitudinal survey, The UK Millennium Cohort Study

\section{Introduction}

Longitudinal surveys are typically challenged by unit non-response, which occurs when respondents drop out from the survey without returning or when they have interrupted patterns of response over time. It results in smaller samples, incomplete histories, lower statistical power, and, more worryingly, in sample bias if the likelihood of dropping out is related to relevant characteristics of respondents. In addition to the problem of refusal, non-contact, and noncooperation, respondents are lost because they cannot be traced. In this paper, the focus is on the link between unit non-response and home moves in the first five waves of the Millennium Cohort Study (MCS) up to age 11 in 2012. In particular, we want to understand to what extent residential mobility is associated with unit non-response.

This paper is written in the context of the Economic and Social Research Council (ESRC) funded project 'Home Moves in Early Years: the impact on children in the UK and the US'. The project uses data from MCS to examine how much, and in what circumstances, moving home can harm or enhance child development (Gambaro \& Joshi, 2016, this issue; and Beck, Buttaro, \& Lennon, 2016, this issue). One of the challenges is that home movers might be under- 
represented among respondents in a longitudinal study like MCS. ${ }^{1}$ The paper attempts to answer two research questions:

1- Are home moves associated with dropout from a longitudinal survey?

2- Is dropout after a home move permanent or transitory?

There is a large literature on the consequences of home moves for child wellbeing (for a review see Jelleyman \& Spencer, 2008). The importance of home moves becomes apparent when their lifelong consequences are laid out (Tønnessen, Telle, \& Syse, 2013). Residential mobility is likely to have an impact on employment, health, and education, especially when moves occur during the school year. These consequences highlight the relevance of this investigation to any longitudinal research dealing with residential mobility and its implications, especially as mobility is likely to lead to bias in sample composition with fewer home movers.

A number of studies such as Böheim and Taylor (2002) and Clark and Huang (2004) provide a description of moves in the UK. Residential mobility has been shown to be higher among unemployed individuals, tenants living in precarious conditions, tenants dissatisfied with their neighbourhoods, and families with young children (Plewis, Ketende, Joshi \& Hughes, 2008). The rates are much lower for other age groups except for young adults aged between 20 and 34. Some of these factors (mainly social disadvantage) are known to be negatively associated with survey response (Mostafa \& Wiggins, 2015) and cooperation with in-survey requests (Mostafa, 2015). However, it remains to be seen whether the impact of residential mobility on response persists after controlling for the socio-demographic characteristics of respondents and whether the effect is permanent in a longitudinal context.

Lepkowski and Couper (2002), Uhrig (2008), and Voorpostel (2010) show that residential mobility is associated with an increased difficulty in tracking respondents and subsequently with higher dropout rates. Similarly, Hawkes and Plewis (2006) show that in the National Child Development Study (NCDS) residential mobility is related to attrition even after controlling for other variables. In a very recent study, Castiglioni and Brix (2014) find that respondents who move between waves are very likely to drop out even in the context of German surveys where population registers are available to fieldwork agencies for tracking purposes. According to Lemay (2009), residential mobility represents a shock event that negatively affects the propensity to take part in a survey since it makes wave on wave contact harder.

Studies specifically on the MCS report similar findings. Plewis et al. (2008) show that in MCS the odds of non-movers remaining in the sample are 1.4 times higher than the odds of those who have moved since the previous wave. Thus, residential mobility was found to contribute to overall non-response after the first wave and possibly to non-contact and noncooperation separately. Calderwood (2010) examines what proportion of families who moved between waves 2 and 3 were successfully located through the study's tracking procedures. The paper also explores the effectiveness of tracking procedures in picking up address changes between waves. Unlike Lemay (2009), it shows that, conditional on being successfully located, movers were not less likely to respond than non-movers. It is also worth noting that the MCS attrition weights take account of residential mobility up to wave 2 , when mobility was at its highest. Although using the attrition weights should correct for bias of initial mobility, they may not eliminate bias if it affects response after wave 2 .

In this study, I am interested in the association between home moves and unit non-response in all five waves of the MCS. The analysis goes beyond the existing literature by examining the impact of home moves on the likelihood of returning to the survey after dropping out in a previous wave.

The next section on data and methods presents the MCS survey and the methods. Section III shows the extent of non-response and residential mobility. Section IV reports the cross-tabulations and regressions relating residential mobility and nonresponse, and the last section concludes.

\section{Data and Methods}

The Millennium Cohort Study (MCS) is a longitudinal survey following a nationally representative, clustered, and stratified sample of 
more than 19,000 children born in the UK in 2000-01. The sample was drawn from all babies born between $1^{\text {st }}$ September 2000 and $31^{\text {st }}$ August 2001 in England and Wales and those born in Scotland and Northern Ireland between $23^{\text {rd }}$ November 2000 and $11^{\text {th }}$ January 2002. MCS has been tracking the cohort members since the age of nine months and survey data have been collected and made available for analysis on five different occasions so far (i.e. age nine months, three, five, seven, and 11 years). The MCS has a complex design - the sample is stratified by country (i.e. England, Scotland, Wales, and Northern Ireland), clustered at the electoral ward level, and has oversampled minorities and disadvantaged groups. In addition to this and like any longitudinal survey, MCS has experienced attrition over time. For more information on sampling, response, and other issues on how to use MCS refer to: Plewis (2007), Ketende (2010), McDonald and Ketende (2010), and Ketende \& Jones (2011).

In this paper, I rely on three groups of binary response models. The first group estimates the effect of residential mobility between two consecutive waves on the likelihood of response in each wave beyond the first. The second group estimates the effect of cumulative residential mobility (i.e. since the start of the survey until the wave of interest) on response in these waves and on participation in all five waves. This group also includes a regression where the data were reshaped into a panel dataset. This regression contrasts the variations in response with those in moving status over time while controlling for wave specific effects (i.e. wave dummy variables). Finally, the third group of models estimates the effect of residential mobility between two consecutive waves on the likelihood of returning to the survey after having been absent in the previous wave. The first two groups of models answer the first research question while the third answers the second.

Two questions about selectivity arise under the different models. First, selection into moving might affect the results if the likelihood to move is confounded by a number of factors. This issue is addressed by including various socio-demographic variables as controls in all regressions. These were selected based on analyses of moving behaviour, (e.g. Böheim \& Taylor, 2002; Gambaro \& Joshi, 2016, this issue) in the literature. However, these covariates, measured at the time of the cohort child's birth, cannot capture the family events in subsequent years (such as partnership break-up, job loss, job gain, or birth of younger siblings) which are shown to trigger moves down the line. This paper examines the impact of moving on response regardless of its particular circumstances. Secondly, in the third group of models, selection into dropping out might be a concern. Since this model estimates the effect of moving on the likelihood of re-joining the survey after having dropped out in the previous wave, the sample will be restricted to those who were absent in a particular wave. As such, those who did not drop out will be excluded and the results will only be valid for a subsample of MCS. In order to address this limitation two types of models are estimated: i) a probit model with a sample restricted to the respondents who have dropped out in a previous wave (some of whom rejoined the study in the following one) and ii) a Heckman selection probit (Heckprobit) model with the entire sample. This model adjusts the findings by taking into account the fact that some respondents who did not drop out, could not re-join the study and therefore were excluded from the first probit model. The finding of the first model is valid for a subsample of the MCS survey while the finding of the Heckprobit model is valid for the entire sample. ${ }^{2}$

\section{Response and residential mobility in MCS}

In what follows, response in MCS between birth and age 11 years is explored. Tables 1 and 2 present the response rates and the patterns of response among those ever interviewed (see Plewis 2007, p.24 for details on sampling respondents from the 27,201 families initially eligible to participate in the study). The base sample consists of the 19,244 families who were interviewed at least once in MCS. Percentages in the following tables are not weighted. 
Table 1. Response rates in the first five waves of MCS

\begin{tabular}{lccccc} 
Response & Wave 1 & Wave 2 & Wave 3 & Wave 4 & Wave 5 \\
\hline Successful response & 96.4 & 81.0 & 79.2 & 72.0 & 69.0 \\
Not issued & 3.6 & 0.0 & 0.0 & 11.5 & 14.8 \\
Ineligible & 0.0 & 0.8 & 1.6 & 0.7 & 0.4 \\
Untraced movers & 0.0 & 3.6 & 2.8 & 3.7 & 2.0 \\
Refusal & 0.0 & 9.0 & 12.0 & 9.4 & 11.4 \\
Non-contact & 0.0 & 4.8 & 2.9 & 0.6 & 2.3 \\
Other & 0.0 & 0.8 & 1.5 & 2.1 & 0.1 \\
\hline Sample size & 19,244 & 19,244 & 19,244 & 19,244 & 19,244 \\
\hline
\end{tabular}

Table 1 shows that the proportion of nonrespondents has increased over time with a dramatic rise between waves 1 and 2 . The 'not issued' category in wave 1 consists of families $(n=692)$ who joined the survey in wave 2 without having been issued in the first wave because their move into an address eligible for the wave 1 was not identified until after the start of the fieldwork. This group, referred to as 'new families', was only recruited in England, and they are known to have moved home between birth and wave 1. From wave 4 onwards, the 'not issued' group includes respondents who had not participated in two consecutive waves. Moreover, families known to have emigrated were designated as ineligible. The ineligible category also includes all families where the cohort child died. The category of untraced movers consists of those who were found to have moved address, but whose new address is unknown, while those in the non-contact category are respondents whose address is known but were not successfully contacted for various reasons (e.g. living in gated communities, long working hours, etc). 'Other' are non-respondents whose moving or emigration status is unknown. Table 1 shows that the proportion of refusals is growing over time, while the proportion of untraced movers and non-contacts is dropping.

\section{Table 2. Response patterns up to wave 5}

\begin{tabular}{lc} 
Response patterns & All waves (\%) \\
\hline All waves & 54.3 \\
Monotone & 26.2 \\
Non-monotone & 19.5 \\
\hline Sample size & 19,244 \\
\hline
\end{tabular}

In table 2, the response patterns are presented. The table shows that the majority of respondents (54.3\%) participated in all five waves, while $26.2 \%$ participated in a number of waves before dropping out without coming back. The remaining $19.5 \%$ of respondents had interrupted response patterns. In other words, they participated in the survey, dropped out, and re-joined the study at a later wave. The relatively large proportion of non-monotone response shows that non-response is not necessarily permanent and could be a transitory phenomenon for some respondents.

In this analysis, residential mobility is constructed as a binary variable taking the value of 1 if the family moved at least once between two consecutive waves and 0 if the family did not move. Mobility is largely based on self-reported answers to whether the family's address is the same as the last interview. The question was asked in all waves, including wave 1 where the question refers to the period since the 
cohort member's birth and the first wave at age 9 months. It should be noted that moving status can be obtained from two different sources: the selfreported questions in the main interview, and the changes to the respondent's address over time (based on the address database). The address database is crucial for providing information on mobility on respondents who do not go on to complete a survey; however, where they do, information is generally consistent across the two sources, but there remain some discrepancies. Very few cases were found to be incorrect in waves 2 and 3 and were adjusted according to the information from the address database.

Information on the number of moves is not taken into account because it is not available in all waves and is not known for non-respondents. It is also worth noting that some respondents had a missing residential mobility status on particular waves because they either dropped out from the study (unit non-response) or they did not answer the mobility question (item non-response). In addition to this, some respondents answered 'don't know'. The missing and 'don't know' cases were imputed as either stayers or movers. Multiple imputations in Stata (i.e. 20 imputations) were carried out. The imputation model was based on the following socio- demographic characteristics measured at birth: age of respondent at interview, cohort member's gender, ethnic group, highest educational qualification (expressed in National Vocational Qualification [NVQ] equivalent levels) in the household, main respondent's work status, housing tenure, breastfeeding, income item non-response, accommodation type, and sampling stratum. These variables are similar to the ones used in the construction of attrition weights in MCS (Ketende, 2010).

Table 3 shows the unweighted proportion of movers and stayers after imputation. The imputation of the variables did not make much difference to the distribution of mobility status. The largest number of moves happened between waves 1 and 2. This is expected as parents are more likely to move into larger accommodation around the time of a birth. Note that the greater number of imputed cases in waves 4 and 5 is due to unit non-response. Moreover, the period of time between two waves is not the same. The period of 27 months between waves 1 and 2 had the largest proportion of moves (40.4\%) even though it is not the longest gap between two waves. The proportion of $21.4 \%$ moving in the last interval ( 4 years) represents a slowdown.

\section{Table 3. Proportion of movers and stayers before and after imputation ${ }^{3}$}

\begin{tabular}{lccccc} 
Residential mobility status & $\begin{array}{c}\text { Between } \\
\text { birth and } \\
\text { wave 1 }\end{array}$ & $\begin{array}{c}\text { Between } \\
\text { waves 1 } \\
\text { and 2 }\end{array}$ & $\begin{array}{c}\text { Between } \\
\text { waves 2 } \\
\text { and 3 }\end{array}$ & $\begin{array}{c}\text { Between } \\
\text { waves 3 } \\
\text { and 4 }\end{array}$ & $\begin{array}{c}\text { Between } \\
\text { waves 4 } \\
\text { and 5 }\end{array}$ \\
\hline Average length of interval (months) & 9 & 27 & 24 & 24 & 48 \\
After Did not move & 83.7 & 59.6 & 77.1 & 89.9 & 78.6 \\
imputation Moved at least once & 16.3 & 40.4 & 22.9 & 10.1 & 21.4 \\
N of imputed cases & 299 & 893 & 1,485 & 5,387 & 6,440 \\
\hline Sample size & 19,244 & 19,244 & 19,244 & 19,244 & 19,244 \\
\hline
\end{tabular}

Table 4 presents the unweighted cumulative proportion of movers and stayers between birth and the wave of interest. The proportion of families who have experienced at least one move rose over time, with the largest increase taking place before wave 2 . By wave 5 (i.e. the age 11 survey), two thirds of the families (68\%) have experienced at least one move. 
Table 4. Cumulative proportion of movers and stayers based on imputed mobility status.

\begin{tabular}{lccccc} 
Moving status & $\begin{array}{c}\text { Between } \\
\text { birth and } \\
\text { wave 1 }\end{array}$ & $\begin{array}{c}\text { Between } \\
\text { birth and } \\
\text { wave 2 }\end{array}$ & $\begin{array}{c}\text { Between } \\
\text { birth and } \\
\text { wave 3 }\end{array}$ & $\begin{array}{c}\text { Between } \\
\text { birth and } \\
\text { wave 4 }\end{array}$ & $\begin{array}{c}\text { Between } \\
\text { birth and } \\
\text { wave 5 }\end{array}$ \\
\hline Did not move & 83.7 & 51.4 & 41.3 & 38.1 & 32.0 \\
Moved at least once & 16.3 & 48.6 & 58.7 & 61.9 & 68.0 \\
\hline Sample size & 19,244 & 19,244 & 19,244 & 19,244 & 19,244 \\
\hline
\end{tabular}

The finding in table 4 is in line with the 2001 census data (standard table 8 ). In MCS, $16.3 \%$ of families moved between birth and age nine months, $40.4 \%$ moved between age nine months and age three years, and $22.9 \%$ moved between age three and five. By summing the three numbers (they add up to $79.6 \%$ ) and dividing them by five we get the average percentage of $15.9 \%$ of families moving at least once in a year. This figure is slightly higher than the $15.3 \%$ obtained from the 2001 census for England and Wales (i.e. $15.3 \%$ of children aged under five lived at a different address the year before the census).

\section{Findings}

Table 5 presents the percentage of movers within each category of response. The percentage of stayers and that of movers add up to $100 \%$. By comparing the percentage of movers (known plus imputed) among respondents and non-respondents with the percentages in table 3 , it is possible to observe the following. First, movers are over-represented among the 'non-contact' category in all waves. Secondly, movers are slightly over-represented among the 'refusal' category in waves 4 and 5 while being underrepresented in waves 2 and 3 . Thirdly, movers are slightly under-represented among the 'ineligible' category in waves 3 and 4 and over-represented in waves 2 and 5 . Fourthly, all untraced movers have by definition moved before dropping out. These findings indicate that residential mobility is associated with non-contact, ineligibility, and untraced categories while being less associated with refusals. In other words, residential mobility is associated with nonresponse categories that can be regarded as circumstantial rather than reflecting an active decision not to participate in the study. This warrants the exploration of the impact of residential mobility on re-joining the survey after dropping out.

Table 5. Residential mobility and response in the five waves of MCS.

\begin{tabular}{lrrrrr} 
Residential mobility status & $\begin{array}{c}\text { Between } \\
\text { birth and } \\
\text { wave 1 }\end{array}$ & $\begin{array}{l}\text { Between } \\
\text { waves 1 } \\
\text { and 2 }\end{array}$ & $\begin{array}{l}\text { Between } \\
\text { waves 2 } \\
\text { and 3 }\end{array}$ & $\begin{array}{l}\text { Between } \\
\text { waves 3 } \\
\text { and 4 }\end{array}$ & $\begin{array}{l}\text { Between } \\
\text { waves 4 } \\
\text { and 5 }\end{array}$ \\
\hline Productive & 13.2 & 38.0 & 21.4 & 9.8 & 20.6 \\
Not Issued & 100.0 & 0.0 & 0.0 & 9.8 & 21.4 \\
Ineligible & 0.0 & 41.2 & 21.7 & 9.4 & 26.9 \\
Untraced Movers & 0.0 & 100.0 & 100.0 & 100.0 & 100.0 \\
Refusal & 0.0 & 36.2 & 18.4 & 11.1 & 23.0 \\
Non-Contact & 0.0 & 43.2 & 25.7 & 12.7 & 27.2 \\
Other & 0.0 & 41.2 & 29.2 & 10.8 & 0.0 \\
\hline
\end{tabular}


Tables 6 and 7 present the odds ratios of a number of logit regression analyses. The dependent variable is the response outcome in each wave. It takes the value of 1 if the family participated in the survey and 0 otherwise.

The choice of the correlates was motivated by the existing literature on non-response and by the choices made previously by Ketende (2008) when the non-response weights in MCS were constructed. In addition to this, controls that are known to be associated with the likelihood of moving homes (Gambaro \& Joshi, 2016, this issue) were chosen in order to reduce the bias resulting from non-random selection into moving.

Only birth characteristics were included in the analyses since they are non-missing for all respondents. The characteristics of new families (i.e. absent in wave 1) were measured in wave 2 . Moreover, some of the categories within the correlates were recoded to avoid small numbers and because in some cases the 'not applicable' category predicted perfectly one of the outcomes.
In table 6, four logit response models are estimated. The independent variable of interest is residential mobility during the period that preceded the survey wave (i.e. the first column of results presents the impact of mobility between waves 1 and 2 on response in wave 2). The findings show that residential mobility has a significant impact on response in waves 2 and 3 with movers being less likely to respond than stayers. The effects in waves 4 and 5 are non-significant. The greatest effect in terms of its magnitude is in wave 2, which is probably caused by the high proportion of families who moved before this wave.

The findings also show that ethnic minorities, nonemployed main respondents, those living in a flat or maisonette, families with boy cohort members, and main respondents who did not answer the income question (wave 2 and 3 ) are less likely to respond. In contrast, more educated main respondents are more likely to respond. 
Table 6. The effect of residential mobility on response

Response wave 2 Response wave 3 Response wave 4

Response wave 5

\begin{tabular}{|c|c|c|c|c|c|c|c|c|}
\hline \multicolumn{9}{|c|}{ Moving status between the wave of interest and the preceding wave (reference: did not move) } \\
\hline Moved at least once & $0.69^{* * *}$ & $(0.029)$ & $0.75^{* * *}$ & $(0.034)$ & 0.98 & $(0.067)$ & 1.01 & (0.051) \\
\hline MR's age at wave 1 & $1.02^{* * *}$ & $(0.004)$ & $1.01^{* * *}$ & $(0.003)$ & $1.02^{* * *}$ & $(0.003)$ & $1.02^{* * *}$ & $(0.003)$ \\
\hline $\mathrm{CM}$ is a boy & $0.91^{*}$ & $(0.035)$ & 0.94 & $(0.034)$ & $0.90^{* *}$ & $(0.030)$ & $0.89^{* * *}$ & $(0.028)$ \\
\hline \multicolumn{9}{|c|}{ MR's ethnic group (reference: White) } \\
\hline Mixed & $0.58^{* *}$ & $(0.097)$ & $0.61^{* *}$ & (0.099) & $0.62^{* *}$ & $(0.096)$ & $0.69^{*}$ & (0.107) \\
\hline Indian & $0.71^{* *}$ & $(0.092)$ & $0.75^{*}$ & $(0.091)$ & $0.78^{*}$ & $(0.086)$ & $0.83^{+}$ & $(0.092)$ \\
\hline Pakistani/Bangladeshi & $0.74^{* *}$ & $(0.069)$ & $0.83^{*}$ & $(0.074)$ & 0.93 & $(0.076)$ & $1.23^{*}$ & $(0.102)$ \\
\hline Black/Black British & $0.51^{* * *}$ & $(0.052)$ & $0.62^{* * *}$ & $(0.063)$ & $0.70^{* * *}$ & $(0.067)$ & $0.66^{* * *}$ & $(0.061)$ \\
\hline Other & $0.57^{* * *}$ & $(0.076)$ & $0.60^{* * *}$ & $(0.078)$ & $0.52^{* * *}$ & $(0.061)$ & $0.72^{* *}$ & (0.087) \\
\hline NA & $11.1^{* * *}$ & $(2.840)$ & 1.16 & $(0.121)$ & 0.98 & (0.088) & 0.92 & (0.079) \\
\hline \multicolumn{9}{|c|}{ Highest educational qualification (NVQ) in the household (reference: NVQ level 1) } \\
\hline NVQ level 5 & 1.16 & $(0.152)$ & $1.48^{* *}$ & $(0.179)$ & $1.48^{* * *}$ & $(0.163)$ & $1.48^{* * *}$ & (0.159) \\
\hline NVQ level 4 & $1.26^{*}$ & $(0.128)$ & $1.62^{* * *}$ & $(0.152)$ & $1.58^{* * *}$ & $(0.136)$ & $1.52^{* * *}$ & (0.129) \\
\hline NVQ level 3 & 1.08 & (0.111) & $1.32^{* *}$ & $(0.127)$ & $1.40^{* * *}$ & $(0.124)$ & $1.28^{* *}$ & (0.111) \\
\hline NVQ level 2 & 0.89 & $(0.086)$ & 1.14 & $(0.102)$ & $1.15^{+}$ & $(0.095)$ & 1.12 & $(0.091)$ \\
\hline Other & $0.81^{+}$ & (0.099) & 1.07 & $(0.123)$ & 0.98 & $(0.103)$ & 0.97 & $(0.101)$ \\
\hline None of these & $0.82^{*}$ & $(0.077)$ & 0.99 & $(0.087)$ & 1.01 & $(0.082)$ & 0.93 & (0.075) \\
\hline \multicolumn{9}{|c|}{ Work status (reference: MR is in work/on leave) } \\
\hline MR not in work & $0.91^{*}$ & $(0.040)$ & $0.84^{* * *}$ & $(0.035)$ & $0.79^{* * *}$ & $(0.030)$ & $0.82^{* * *}$ & $(0.030)$ \\
\hline \multicolumn{9}{|c|}{ Housing tenure (reference: own outright ) } \\
\hline Own - mortgage/loan & 0.99 & (0.109) & $1.21^{+}$ & $(0.117)$ & 1.08 & $(0.097)$ & 1.13 & (0.098) \\
\hline Part rent/part mortgage & 0.74 & $(0.218)$ & 1.31 & $(0.398)$ & 1.36 & $(0.386)$ & 0.98 & $(0.250)$ \\
\hline Rent from local authority & 0.84 & (0.098) & 1.17 & $(0.122)$ & 0.96 & (0.093) & 1.02 & $(0.096)$ \\
\hline Rent from Housing & $0.76^{*}$ & (0.094) & 1.13 & $(0.128)$ & 0.93 & (0.098) & 0.97 & $(0.100)$ \\
\hline \multicolumn{9}{|l|}{ Association } \\
\hline Rent privately & $0.70^{* *}$ & $(0.085)$ & 1.04 & $(0.115)$ & 0.87 & $(0.089)$ & 0.93 & (0.093) \\
\hline Living with parents & 0.90 & $(0.123)$ & 1.18 & $(0.148)$ & 0.90 & $(0.104)$ & 0.95 & (0.107) \\
\hline Live rent free & 0.89 & $(0.180)$ & 1.11 & $(0.213)$ & 0.91 & (0.159) & 1.04 & $(0.180)$ \\
\hline Other & $0.44^{* * *}$ & (0.084) & $0.69^{*}$ & (0.124) & $0.73^{+}$ & $(0.125)$ & 1.02 & (0.174) \\
\hline
\end{tabular}




\begin{tabular}{|c|c|c|c|c|c|c|c|c|}
\hline $\begin{array}{l}\text { Breastfeeding attempted } \\
\text { Income item non-response }\end{array}$ & $\begin{array}{l}1.46^{* * *} \\
0.82^{* *}\end{array}$ & $\begin{array}{l}(0.063) \\
(0.054)\end{array}$ & $\begin{array}{l}1.40^{* * *} \\
0.83^{* *}\end{array}$ & $\begin{array}{l}(0.058) \\
(0.053)\end{array}$ & $\begin{array}{l}1.31^{* * *} \\
0.83^{* *}\end{array}$ & $\begin{array}{l}(0.050) \\
(0.049)\end{array}$ & $\begin{array}{l}1.35^{* * *} \\
0.81^{* * *}\end{array}$ & $\begin{array}{l}(0.050) \\
(0.047)\end{array}$ \\
\hline \multicolumn{9}{|c|}{ Accommodation type (reference: a house or bungalow) } \\
\hline A flat or maisonette & $0.68^{* * *}$ & $(0.037)$ & $0.86^{* *}$ & $(0.047)$ & $0.82^{* * *}$ & $(0.041)$ & $0.85^{* * *}$ & $(0.042)$ \\
\hline Other & $0.55^{* *}$ & $(0.103)$ & $0.71^{+}$ & $(0.128)$ & 0.81 & (0.139) & $0.66^{*}$ & $(0.112)$ \\
\hline \multicolumn{9}{|c|}{ Stratum (reference England-Advantaged) } \\
\hline England - Disadvantaged & $0.89^{*}$ & $(0.054)$ & $0.89^{*}$ & $(0.050)$ & $0.88^{* *}$ & $(0.044)$ & 1.02 & $(0.049)$ \\
\hline England - Ethnic & $0.85^{*}$ & $(0.072)$ & $0.84^{*}$ & $(0.066)$ & $0.84^{*}$ & $(0.060)$ & 0.98 & (0.069) \\
\hline Wales - Advantaged & $0.77^{*}$ & $(0.081)$ & $0.75^{* *}$ & $(0.073)$ & $0.79^{* *}$ & $(0.070)$ & $0.86^{+}$ & (0.073) \\
\hline Wales - Disadvantaged & 0.98 & $(0.075)$ & $0.88^{+}$ & $(0.063)$ & 0.95 & $(0.062)$ & $0.90^{+}$ & $(0.055)$ \\
\hline Scotland - Advantaged & $0.71^{* * *}$ & $(0.064)$ & $0.78^{* *}$ & $(0.067)$ & $0.73^{* * *}$ & $(0.056)$ & $0.72^{* * *}$ & (0.053) \\
\hline Scotland - Disadvantaged & $0.66^{* * *}$ & $(0.055)$ & $0.76^{* * *}$ & (0.063) & $0.74^{* * *}$ & (0.056) & $0.65^{* * *}$ & (0.047) \\
\hline $\mathrm{NI}$ - Advantaged & $0.64^{* * *}$ & $(0.069)$ & 0.87 & $(0.093)$ & $0.75^{* *}$ & $(0.071)$ & $0.76^{* *}$ & $(0.068)$ \\
\hline $\mathrm{NI}$ - Disadvantaged & $0.57^{* * *}$ & $(0.047)$ & 0.93 & $(0.078)$ & $0.85^{*}$ & $(0.064)$ & 0.97 & $(0.071)$ \\
\hline$N$ & \multicolumn{2}{|c|}{19,244} & \multicolumn{2}{|c|}{19,244} & \multicolumn{2}{|c|}{19,244} & \multicolumn{2}{|c|}{19,244} \\
\hline
\end{tabular}

Exponentiated coefficients; Standard errors in parentheses, ${ }^{+} p<0.10,{ }^{*} p<0.05,{ }^{* *} p<0.01,{ }^{* * *} p<0.001$. CM stands for cohort member and MR for main respondent. 
Table 7 presents the odds ratios from five crosssectional logit response models and one logit model with pooled data over time. In the cross-sectional models, the independent variable of interest is cumulative residential mobility between the cohort member's birth and the wave in which response is sought. In the pooled regression, the data is restructured into a panel dataset and a response model is estimated with wave dummy variables. Note that in this model, only moving status varies over time while all other controls are measured at birth and are time invariant. The controls included in all regressions are the same as those in table 6 and they generated similar results. Therefore, only the results on moving status and on the wave dummy variables are reported.

The findings show that those who have moved at least once between the cohort member's birth and the wave of interest are less likely to respond in waves 2, 3 and 4 . Those who have moved at least once between birth and wave 5 are also less likely to participate in all five waves. Furthermore, even after controlling for wave-specific factors in the pooled regression, those who have moved at least once since the start of the survey are found to be less likely to respond. 


\section{Table 7. The cumulative effect of residential mobility on response}

\begin{tabular}{|c|c|c|c|c|c|c|c|c|c|c|c|}
\hline \multirow{2}{*}{\multicolumn{2}{|c|}{$\begin{array}{r}\text { Response wave } 2 \\
\text { Moving status since birth (reference: } \text { did not move) }\end{array}$}} & \multicolumn{2}{|c|}{ Response wave 3} & \multicolumn{2}{|c|}{ Response wave 4} & \multicolumn{2}{|c|}{ Response wave 5} & \multicolumn{2}{|c|}{ All waves } & \multicolumn{2}{|c|}{ Pooled Logit } \\
\hline & & & & & & & & & & & \\
\hline Moved at least once & $0.72^{* * *} \quad(0.031)$ & $0.90^{*}$ & $(0.038)$ & $0.92^{+}$ & $(0.037)$ & 0.94 & $(0.038)$ & $0.73^{* * *}$ & $(0.028)$ & $0.41^{* * *}$ & $(0.009)$ \\
\hline \multirow{2}{*}{\multicolumn{12}{|c|}{$\begin{array}{l}\text { All models include the same controls as in table } 6\end{array}$}} \\
\hline & & & & & & & & & & & \\
\hline \multicolumn{12}{|c|}{$\ldots$} \\
\hline \multicolumn{12}{|c|}{ Wave dummies (reference: Wave 2) } \\
\hline Wave 3 & & & & & & & & & & 0.98 & $(0.026)$ \\
\hline Wave 4 & & & & & & & & & & $0.70^{* * *}$ & $(0.018)$ \\
\hline Wave 5 & & & & & & & & & & $0.64^{* * *}$ & $(0.016)$ \\
\hline$N$ & 19,244 & & & & & & & 19 , & & & 76 \\
\hline
\end{tabular}

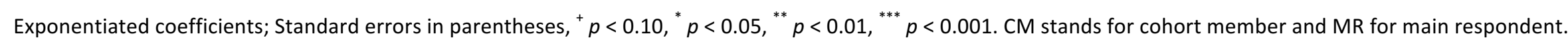


Table 8 presents the results of six probit models that measure the impact of mobility on the likelihood of re-joining the survey after dropping-out. The independent variable of interest is residential mobility during the period that preceded drop-out from the survey (measured since the beginning of the survey). Two types of models are estimated: i) a probit model with a sample restricted to the respondents who have dropped out in a previous wave and ii) a Heckman selection probit (Heckprobit) model with the entire sample. This model adjusts the findings by taking into account selection into dropping out in a particular wave.

The working assumption behind these models is that residential mobility is circumstantial and even if it leads to drop out in one wave it should not prevent respondents from joining the survey on a future occasion. The findings show that respondents who dropped out from the study in wave 2 are more likely to return in wave 3 if they have moved homes during the period preceding the drop out. The effect is nonsignificant for returning at waves 4 and 5 . In the adjusted model, the effect is smaller in magnitude but remains significant for those absent in wave 2 . Note that the non-significant effects are on the waves in which moving was found not to be associated with response (table 6). The results of both models, unadjusted and adjusted for selection, are substantively valid depending on the respondents of interest. The first model is valid for the subsample of respondents who dropped out in a particular wave, and the second is valid for the entire sample.

Moreover, the results suggest that the effect of home moves on response are transitory and will only affect response if they overlap with the data collection phase. In other words, the effect of residential mobility is different in nature from the effect of the personal characteristics of respondents (e.g. ethnicity, social class, personality, and predispositions). These characteristics are expected to have a persistent effect on response in each wave. The findings also demonstrate the importance of tracing non-respondents and maintaining the address database since successful response is likely to be achieved on a future occasion if residential mobility was the reason for drop out and if families' new whereabouts can be established. This finding also supports reissuing the not-issued cases at certain point in the survey's life. 
Table 8. The impact of residential mobility on the likelihood of coming back to the survey

\begin{tabular}{|c|c|c|c|c|c|c|c|c|c|c|c|c|}
\hline & \multicolumn{2}{|c|}{$\begin{array}{c}\text { Probit } \\
\text { Absent in wave } 2\end{array}$} & \multicolumn{2}{|c|}{$\begin{array}{c}\text { Heckprobit } \\
\text { Absent in wave } 2 \\
\end{array}$} & \multicolumn{2}{|c|}{$\begin{array}{c}\text { Probit } \\
\text { Absent in wave } 3 \\
\end{array}$} & \multicolumn{2}{|c|}{$\begin{array}{c}\text { Heckprobit } \\
\text { Absent in wave } 3\end{array}$} & \multicolumn{2}{|c|}{$\begin{array}{c}\text { Probit } \\
\text { Absent in wave } 4\end{array}$} & \multicolumn{2}{|c|}{$\begin{array}{c}\text { Heckprobit } \\
\text { Absent in wave } 4\end{array}$} \\
\hline \multicolumn{13}{|c|}{ Moving status before dropping out (reference: did not move) } \\
\hline Moved at least once & $0.28^{* * *}$ & $(0.046)$ & $0.16^{* * *}$ & $(0.025)$ & -0.088 & $(0.071)$ & -0.046 & $(0.036)$ & 0.15 & $(0.101)$ & 0.14 & $(0.146)$ \\
\hline MR's age at wave 1 & -0.0040 & $(0.004)$ & $0.014^{* *}$ & $(0.003)$ & -0.00038 & $(0.006)$ & $-0.013^{* * *}$ & $(0.004)$ & 0.0035 & $(0.005)$ & -0.0046 & $(0.029)$ \\
\hline CM is a boy & -0.037 & $(0.043)$ & 0.018 & $(0.028)$ & -0.052 & $(0.061)$ & -0.0092 & $(0.038)$ & $0.087^{+}$ & $(0.049)$ & $0.100^{*}$ & $(0.046)$ \\
\hline \multicolumn{13}{|c|}{ MR's ethnic group (reference: White) } \\
\hline Mixed & 0.15 & $(0.173)$ & $0.30^{*}$ & $(0.120)$ & 0.036 & $(0.234)$ & $0.32^{*}$ & $(0.157)$ & -0.050 & (0.199) & 0.058 & $(0.426)$ \\
\hline Indian & 0.11 & $(0.144)$ & $0.18^{+}$ & $(0.094)$ & 0.036 & $(0.201)$ & 0.13 & $(0.125)$ & -0.086 & (0.169) & -0.047 & (0.229) \\
\hline Pakistani/Bangladeshi & $0.21^{*}$ & $(0.103)$ & $0.22^{* *}$ & $(0.067)$ & $0.42^{* *}$ & $(0.135)$ & $0.33^{* * *}$ & $(0.086)$ & $0.40^{* * *}$ & $(0.117)$ & 0.38 & $(0.234)$ \\
\hline Black/Black British & 0.17 & $(0.106)$ & $0.37^{* * *}$ & $(0.072)$ & 0.23 & $(0.153)$ & $0.38^{* * *}$ & $(0.097)$ & 0.084 & $(0.129)$ & 0.17 & $(0.300)$ \\
\hline Other & -0.21 & $(0.143)$ & 0.10 & (0.103) & $-0.56^{*}$ & $(0.234)$ & -0.12 & $(0.168)$ & 0.18 & $(0.157)$ & 0.31 & (0.407) \\
\hline NA & -0.12 & $(0.344)$ & $-1.00^{* * *}$ & $(0.180)$ & 0.066 & $(0.158)$ & 0.11 & $(0.098)$ & 0.068 & $(0.120)$ & 0.11 & (0.156) \\
\hline \multicolumn{13}{|c|}{ Highest educational status in the household (reference: NVQ level 1) } \\
\hline NVQ level 5 & $0.22^{*}$ & $(0.107)$ & $0.16^{*}$ & $(0.072)$ & -0.026 & $(0.136)$ & -0.081 & $(0.088)$ & -0.012 & $(0.110)$ & -0.032 & (0.119) \\
\hline NVQ level 4 & $0.19^{+}$ & $(0.115)$ & 0.067 & $(0.076)$ & 0.20 & $(0.145)$ & -0.017 & $(0.095)$ & -0.026 & $(0.122)$ & -0.10 & $(0.270)$ \\
\hline NVQ level 3 & 0.18 & $(0.113)$ & 0.0053 & $(0.075)$ & 0.096 & $(0.146)$ & $-0.20^{*}$ & $(0.094)$ & -0.016 & $(0.120)$ & -0.13 & (0.414) \\
\hline NVQ level 2 & 0.19 & $(0.150)$ & 0.051 & $(0.096)$ & 0.14 & $(0.218)$ & -0.19 & $(0.131)$ & 0.16 & $(0.181)$ & 0.011 & (0.615) \\
\hline Other & 0.18 & $(0.134)$ & $0.18^{+}$ & $(0.091)$ & -0.17 & $(0.182)$ & -0.15 & $(0.117)$ & -0.077 & $(0.144)$ & -0.065 & (0.149) \\
\hline None of these & 0.13 & $(0.104)$ & $0.15^{*}$ & $(0.071)$ & -0.017 & $(0.131)$ & -0.042 & $(0.086)$ & -0.086 & $(0.107)$ & -0.065 & (0.143) \\
\hline \multicolumn{13}{|c|}{ Work status (reference: MR is in work/on leave) } \\
\hline MR not in work & -0.069 & $(0.050)$ & 0.0030 & $(0.032)$ & $-0.16^{*}$ & $(0.072)$ & -0.014 & $(0.046)$ & -0.034 & $(0.057)$ & 0.0097 & $(0.170)$ \\
\hline \multicolumn{13}{|c|}{ Housing tenure (reference: own outright ) } \\
\hline Own - mortgage/loan & 0.076 & $(0.130)$ & 0.065 & $(0.084)$ & 0.028 & $(0.157)$ & -0.14 & $(0.097)$ & 0.15 & $(0.145)$ & 0.11 & (0.249) \\
\hline Part rent/part mortgage & 0.20 & $(0.323)$ & 0.25 & $(0.211)$ & $0.81^{+}$ & $(0.475)$ & 0.25 & $(0.287)$ & -0.30 & (0.499) & -0.36 & $(0.468)$ \\
\hline Rent from local authority & $0.25^{+}$ & $(0.136)$ & $0.23^{*}$ & $(0.089)$ & 0.034 & $(0.165)$ & -0.065 & $(0.103)$ & 0.18 & $(0.151)$ & 0.20 & (0.141) \\
\hline Rent from Housing & $0.24^{+}$ & $(0.144)$ & $0.28^{* *}$ & $(0.094)$ & -0.0075 & $(0.179)$ & -0.067 & $(0.112)$ & 0.11 & $(0.160)$ & 0.15 & $(0.160)$ \\
\hline \multicolumn{13}{|l|}{ Association } \\
\hline Rent privately & 0.22 & $(0.141)$ & $0.33^{* * *}$ & $(0.092)$ & 0.023 & $(0.175)$ & 0.016 & (0.109) & 0.056 & $(0.157)$ & 0.11 & $(0.214)$ \\
\hline Living with parents & 0.21 & $(0.155)$ & $0.20^{*}$ & $(0.101)$ & -0.17 & $(0.198)$ & -0.18 & $(0.125)$ & 0.047 & $(0.173)$ & 0.071 & $(0.170)$ \\
\hline Live rent free & 0.33 & $(0.224)$ & $0.25^{+}$ & $(0.144)$ & -0.10 & $(0.299)$ & -0.12 & $(0.193)$ & $0.57^{*}$ & $(0.252)$ & $0.57^{+}$ & $(0.307)$ \\
\hline Other & -0.019 & $(0.207)$ & $0.36^{*}$ & $(0.148)$ & 0.37 & $(0.286)$ & $0.30^{+}$ & $(0.180)$ & $0.71^{*}$ & $(0.277)$ & 0.69 & (0.431) \\
\hline Breastfeeding attempted & 0.052 & $(0.048)$ & $-0.13^{* * *}$ & $(0.031)$ & $0.12^{+}$ & $(0.068)$ & $-0.087^{+}$ & $(0.044)$ & $0.096^{+}$ & $(0.056)$ & 0.033 & $(0.254)$ \\
\hline
\end{tabular}




\begin{tabular}{|c|c|c|c|c|c|c|c|c|c|c|c|c|}
\hline $\begin{array}{l}\text { Income item non- } \\
\text { response }\end{array}$ & -0.019 & $(0.071)$ & 0.071 & $(0.048)$ & -0.12 & $(0.110)$ & -0.035 & (0.069) & $-0.17^{+}$ & $(0.088)$ & -0.13 & $(0.208)$ \\
\hline \multicolumn{13}{|c|}{ Accommodation type (reference: a house or bungalow) } \\
\hline A flat or maisonette & 0.062 & $(0.059)$ & $0.21^{* * *}$ & $(0.040)$ & -0.064 & $(0.087)$ & 0.075 & $(0.056)$ & -0.027 & $(0.069)$ & 0.040 & $(0.248)$ \\
\hline Other & -0.034 & $(0.192)$ & $0.26^{+}$ & $(0.140)$ & $-0.53^{+}$ & $(0.304)$ & -0.20 & $(0.211)$ & $-0.52^{+}$ & $(0.272)$ & -0.45 & $(0.482)$ \\
\hline \multicolumn{13}{|c|}{ Stratum (reference England-Advantaged) } \\
\hline England - Disadvantaged & $0.14^{* 0}$ & $(0.070)$ & $0.12^{* *}$ & $(0.045)$ & 0.14 & $(0.098)$ & $0.13^{*}$ & $(0.059)$ & 0.054 & $(0.077)$ & 0.11 & $(0.186)$ \\
\hline England - Ethnic & 0.11 & (0.093) & $0.13^{*}$ & $(0.061)$ & 0.13 & $(0.124)$ & $0.16^{*}$ & (0.079) & 0.100 & $(0.102)$ & 0.16 & $(0.197)$ \\
\hline Wales - Advantaged & 0.034 & (0.123) & $0.13^{+}$ & $(0.080)$ & $0.35^{*}$ & $(0.173)$ & $0.28^{* *}$ & (0.102) & -0.033 & (0.141) & 0.051 & $(0.325)$ \\
\hline Wales - Disadvantaged & 0.055 & (0.089) & 0.058 & $(0.057)$ & $0.27^{*}$ & $(0.121)$ & $0.21^{* *}$ & $(0.074)$ & -0.073 & (0.097) & -0.018 & $(0.234)$ \\
\hline Scotland - Advantaged & 0.13 & (0.104) & $0.21^{* *}$ & $(0.067)$ & 0.059 & $(0.160)$ & 0.11 & (0.095) & -0.17 & $(0.132)$ & -0.096 & $(0.339)$ \\
\hline Scotland - Disadvantaged & $0.28^{* *}$ & (0.094) & $0.32^{* * *}$ & $(0.062)$ & 0.10 & $(0.136)$ & $0.21^{*}$ & $(0.085)$ & $-0.27^{*}$ & (0.115) & -0.17 & $(0.463)$ \\
\hline $\mathrm{NI}$ - Advantaged & $0.34^{* *}$ & $(0.122)$ & $0.37^{* * *}$ & $(0.077)$ & -0.18 & $(0.232)$ & -0.13 & $(0.137)$ & -0.20 & $(0.163)$ & -0.12 & $(0.378)$ \\
\hline $\mathrm{NI}$ - Disadvantaged & $0.45^{* * *}$ & $(0.091)$ & $0.47^{* * *}$ & $(0.059)$ & 0.11 & $(0.146)$ & 0.092 & $(0.089)$ & -0.0004 & $(0.113)$ & 0.057 & $(0.217)$ \\
\hline Constant & $-0.80^{* * *}$ & $(0.214)$ & $-1.56^{* * *}$ & $(0.140)$ & $-0.47^{+}$ & $(0.276)$ & $-1.31^{* * *}$ & $(0.173)$ & $-0.56^{*}$ & $(0.247)$ & -1.07 & $(1.483)$ \\
\hline Censored & & & \multicolumn{2}{|c|}{15,590} & \multirow{2}{*}{\multicolumn{6}{|c|}{$\begin{array}{c}15,142 \\
1,889\end{array}$}} & \multicolumn{2}{|c|}{13,649} \\
\hline \multicolumn{3}{|l|}{ Uncensored } & \multicolumn{2}{|c|}{3,654} & & & & & & & \multicolumn{2}{|c|}{2,744} \\
\hline$N$ & \multicolumn{2}{|c|}{3,654} & \multicolumn{2}{|c|}{19,244} & \multicolumn{2}{|c|}{1,889} & \multicolumn{2}{|c|}{17,031} & \multicolumn{2}{|c|}{2,744} & \multicolumn{2}{|c|}{16,393} \\
\hline
\end{tabular}

Exponentiated coefficients; Standard errors in parentheses, ${ }^{+} p<0.10,{ }^{*} p<0.05,{ }^{* *} p<0.01,{ }^{* * *} p<0.001$. CM stands for cohort member and MR for main respondent. 


\section{Conclusion}

This paper examined the impact of home moves in the first 11 years on response in the MCS longitudinal survey. The findings show that residential mobility is not a cause of permanent non-response. In other words, movers who dropped out in a previous wave can reappear in subsequent waves. This finding goes beyond the existing literature since it shows that the impact of home moves on survey response may be only short-term. This impact depends on the importance given to tracing non-respondents and encouraging their co-operation. The Millennium Cohort Study is a testimony to the success of these efforts. Non-respondents are very likely to come back if the reason for dropping out, or not being found in time, was moving home around the time of the survey, provided that their new address is ascertained. As shown by Gambaro \& Joshi (2016, this issue), most home moves are local and happen in reasonably favourable circumstances, which would have made contact easier to maintain than moves over longer distances and under distressed circumstances.

Moreover, the paper showed that residential mobility of families with young children is nevertheless likely to be a challenge for longitudinal birth cohorts. Movers are more likely to be missing from the early waves of a longitudinal survey and less likely to be missing from later waves. This is consistent with the literature (Clark \& Huang 2004; and Plewis et al. 2008) and with the fact that most moves happen in the early years after the birth of the child when parents are particularly likely to be looking for bigger or better accommodation.

Looking beyond MCS, the results of this paper can be generalised to other studies since longitudinal surveys are likely to face dropout due to home moves, even though the effect of residential mobility is transitory. The success of bringing these attriters back to the survey will depend on the effectiveness of the tracing efforts.

For data users interested in residential mobility, the association between mobility and response requires an adjustment for sample bias. The standard MCS attrition weights take mobility into account up till wave 2 , but they do not take it into account from wave 3 onwards. Using the standard weights at wave 3 will understate bias due to the recent drop-outs among movers. Similarly, using the weights for wave 3 will overstate the bias caused by moving due to the movers who re-joined the survey.

\section{Acknowledgements}

This project is supported by grant ES/K000438/1 from the Economic and Social Research Council (ESRC); (see: http://www.ioe.ac.uk/research/departments/qss/87492.html). The author would like to thank the MCS data and survey management teams for granting him access to home move information derived from the respondents' address database. He would also like to thank Heather Joshi, Mary Clare Lennon, Anthony Buttaro, Ludovica Gambaro and William Clark for their valuable comments.

\section{References}

Beck, B. Buttaro, A. \& Lennon, M.C. (2016). Home moves and child well-being in the first five years of life in the United States. Longitudinal and Life Course Studies 6(3), 240-264.

http://dx.doi.org/10.14301/llcs.v7i3.374

Böheim R., \& Taylor, M. (2002). Tied Down or Room to Move? Investigating the Relationships between Housing Tenure, Employment Status and Residential Mobility in Britain. Scottish Journal of Political Economy, 49(4), 369-392. http://dx.doi.org/10.1111/1467-9485.00237

Castiglioni, L. \& Brix, J. (2014). Does Moving Increase Panel Attrition? An Assessment Based on Paradata. Paper presented at the Panel Survey Methods Workshop, University of Michigan.

Calderwood, L. (2010). Keeping in Touch with Mobile Families in the UK Millennium Cohort Study (Working Paper No 2010/7). London, UK: Centre for Longitudinal Studies. 
Clark W. A. V. \& Huang Y. (2004). Linking migration and mobility: individual and contextual effects in housing markets in the UK, Regional Studies 38, 617-628. http://dx.doi.org/10.1080/003434042000240932

Gambaro , L. \& Joshi, H. (2016). Moving home in the early years: What happens to children in the UK? Longitudinal and Life Course Studies 6(3), 265-287. http://dx.doi.org/10.14301/llcs.v7i3.375

Hawkes, D. \& Plewis, I. (2006). Modelling Nonresponse in the National Child Development Study. Journal of the Royal Statistical Society, Series A, 169, 479-491. http://dx.doi.org/10.1111/j.1467-985X.2006.00401.x

Jelleyman, T. \& Spencer, N. (2008). Residential mobility in childhood and health outcomes: a systematic review. Journal of Epidemiology and Community Health 62, 584-592. http://dx.doi.org/10.1136/jech.2007.060103

Ketende, S.C. (2010). (Ed.). Millennium Cohort Study: Technical Report on Response ( $3^{\text {rd }}$ ed.). London, UK: Centre for Longitudinal Studies. Retrieved from http://www.cls.ioe.ac.uk/shared/getfile. ashx?id=607\&itemtype=document

Ketende, S.C. \& Jones, E.M. (2011). The Millennium Cohort Study. User Guide to Analysing MCS Data Using STATA ( $1^{\text {st }}$ ed.). London, UK: Centre for Longitudinal Studies. Retrieved from http://www.cls.ioe.ac.uk/shared/get-file.ashx?id=1372\&itemtype=document

Lemay, M. (2009). Understanding the Mechanism of Panel Attrition. (Unpublished Doctoral Dissertation). University of Maryland.

Lepkowski, J. \& Couper, M. (2002). Non-response in the Second Wave of Longitudinal Household Surveys. In R. Groves, D. Dillman, J. L. Eltinge, \& Little, R. J. (Eds.), Survey Nonresponse (pp. 259-274). New York: John Wiley \& Sons.

McDonald, J., \& Ketende, S. (2010). Nonresponse Weight Adjustments Using Multiple Imputation for the UK Millennium Cohort Study. CLS working paper N 2010/6. London, UK: Centre for Longitudinal Studies.

Mostafa, T. (2015). Variation within Households in Consent to Link Survey Data to Administrative Records: Evidence from the UK Millennium Cohort Study. International Journal of Social Research Methodology, published online on: 23 March 2015. http://dx.doi.org/10.1080/13645579.2015.1019264

Mostafa, T. and Wiggins, D. (2015). The Impact of Attrition and Non-response in Birth Cohort Studies: Raising the Need to Incorporate Strategies to Handle Missingness in Longitudinal Analyses. Longitudinal and Life Course Studies 6(2), 131-146. http://dx.doi.org/10.14301/llcs.v6i2.312

Plewis, I. (2007). (Ed). The Millennium Cohort Study: Technical Report on Sampling (4 ${ }^{\text {th }}$ ed.). London, UK: Centre for Longitudinal Studies. Retrieved from http://www.cls.ioe.ac.uk/shared/getfile. ashx?id=409\&itemtype=document

Plewis, I., Ketende, S., Joshi, H., \& Hughes, G. (2008). The Contribution of Residential Mobility to Sample Loss in a Birth Cohort Study: Evidence from the First Two Waves of the UK Millennium Cohort Study. Journal of Official Statistics 24(3), 365-385.

Tønnessen, M., Telle, K., \& Syse, A. (2013). Childhood residential mobility and adult outcomes, Discussion Paper 750, Statistics Norway, Research Department. Retrieved from http://www.ssb.no/en/forskning/discussion-papers/childhood-residential-mobility-and-adult-outcomes

Uhrig, N. (2008). The Nature and Causes of Attrition in the British Household Panel Survey. Institute for Social and Economic Research Working Paper, 2008(5). Retreived from https://www.iser.essex.ac.uk/research/publications/working-papers/iser/2008-05

Voorpostel, M. (2010). Attrition Patterns in the Swiss Household Panel by Demographic Characteristics and Social Involvement. Panelattrition im Schweizer Haushalt-Panel: Eine Analyse nach demographischen Merkmalen und sozialer Inklusion 36(2), 359-377. 


\section{Endnotes}

${ }^{1}$ In MCS the characteristics of non-responders are known from previous waves, especially waves 1 and 2 in which most families participated. This information is not available for Fragile Families and Child Wellbeing Study (FFCWS).

${ }^{2}$ Note that in the last group of models, I have resorted to a probit specification since logistic regressions are not supported by the Heckman selection approach in Stata.

${ }^{3}$ The proportions in tables 3 and 4 are unweighted and the analytical sample consists of all 19,244 families ever interviewed in MCS. Moreover, the cases with missing residential mobility status were fully imputed. The numbers differ from those in Gambaro \& Joshi (this issue) because they are unweighted and are based on a larger sample. 